\title{
MINIMALLY INVASIVE EXTREME LATERAL APPROACH IN SPINAL LUMBAR METASTASIS
}

\section{VIA EXTREMO LATERAL MINIMAMENTE INVASIVA EM CASOS DE METASTASES LOMBARES}

\author{
lucas Castrillon Carmo Machado ${ }^{1}$, Douglas Kenu Narazaki ${ }^{1}$, Willian Gemio Jacobsen Teixeira ${ }^{1}$, Alexandre Fogaça Ristante $^{1}$, \\ Manoel Jacobsen Teixeira ${ }^{1}$, Tarcisio Eloy Pessoa de Barros Filho ${ }^{1}$
}

1. Institute of Orthopedics and Traumatology, Hospital das Clínicas da Faculdade de Medicina da Universidade de São Paulo (IOT-HCFMUSP), São Paulo, Brazil.

\begin{abstract}
Introduction: The extreme lateral approach has been widely used for the treatment of degenerative diseases. The objective of this study is to present a minimally invasive extreme lateral approach for the treatment of metastatic lesions in the lumbar spine without the use of the evoked potential exam (MEP). Methods: Two patients with spinal metastases and indication for surgery via the anterior approach were treated in a cancer referral center in Brazil. They were placed in right lateral decubitus, and an oblique incision was made, exposing the psoas muscle. The anterior approach permitted the release of the psoas muscle from vertebral body and disc, without the need for MEP. Conclusions: When cancer cure is no longer possible, a minimally invasive extreme lateral approach to treat tumor metastases in the lumbar spine is a viable option, with short hospitalization time and low morbidity. The dislocation of the psoas muscle avoids the use of the transpsoas approach, which requires MEP equipment and a trained physician. Clinical studies are needed to extend these benefits to oncological patients who have treatment options for their primary disease. Level of Evidence IV; Case series.
\end{abstract}

Keywords: Minimally invasive surgical procedures. Neoplasms. Neoplasm metastasis. Spine. Spinal fusion. Operative surgical procedures.

\section{RESUMO}

Introdução: A técnica extremo-lateral já vem sendo amplamente usada no tratamento de doenças degenerativas fazendo com que o objetivo deste trabalho seja de apresentar a técnica extremo-lateral minimamente invasiva para o tratamento de metástases na coluna lombar, sem a necessidade do potencial evocado motor (MEP). Método: Dois pacientes com metástases em coluna com indicação para cirurgia pelo acesso anterior foram tratados em um centro de referência no Brasil. Eles foram posicionados em decúbito lateral direito e uma incisão oblíqua foi feita, expondo o músculo psoas. Pela via anterior, foi possível descolar as fibras do músculo psoas do corpo vertebral e disco, sem a ajuda do MEP. Conclusão: Quando a cura do câncer não é possível, o acesso extremo lateral por cirurgia minimamente invasiva é uma opção viável no tratamento de metástases tumorais na coluna lombar, com hospitalização curta e baixa morbidade. O descolamento do psoas evita o uso da via transpsoas, que exigiria a assistência com equipamento de MEP e profissional treinado para operá-lo. Estudos clínicos são necessários para que esses benefícios sejam estendidos a pacientes com câncer, para que ainda haja opção de tratamento para a doença primária. Nível de Evidência IV; Série de casos.

Descritores: Procedimentos cirúrgicos minimamente invasivos. Neoplasias. Metástase neoplásica. Coluna vertebral. Fusão vertebral. Procedimentos cirúrgicos operatórios.

Citation: Machado LCC, Narazaki DK, Teixeira WGJ, Cristante AF, Teixeira MJ, Barros Filho TEP. Minimally invasive extreme lateral approach in spinal lumbar metastasis. Acta Ortop Bras. [online]. 2018;26(3):191-3. Available from URL: http://www.scielo.br/aob.

\section{INTRODUCTION}

Metastatic lesions account for $97 \%$ of spine tumors and in these cases, due to the involvement of the vertebral body, intervention by the anterior or posterolateral transpedicular approach is required. For these cases, an extreme lateral approach using a minimally invasive technique (MIS), widely used for degenerative diseases, is a natural option, offering the same advantages with lower patient morbidity. The extreme lateral approach was described for the treatment of spine pathologies by Ozgur et al. ${ }^{1}$ in 2006 , with a focus on degenerative pathologies of the spine. The technical advantages noted were: no need for postoperative hospitalization in the intensive care unit (ICU), earlier return to walking, the possibility of the surgery being performed by the team of spine surgeons, without the need for a general surgeon, little need for blood components, and a lower rate of local complications. ${ }^{1}$ With the improvement of the method and learning curve, it was possible to expand its application to other diseases, such as degenerative adult lumbar scoliosis and low-grade spondylolisthesis. . $^{2-4}$

This technique, previously restricted to the lumbar region, has proved to be feasible for the thoracic region and thoracolumbar transition. ${ }^{5}$

All authors declare no potential conflict of interest related to this article.

Study conducted at the Department of Orthopedics and Traumatology, Hospital das Clínicas, Faculdade de Medicina da Universidade de São Paulo, Brazil.

Correspondence: Alexandre Fogaça Cristante. Rua Dr. Ovídio Pires de Matos, 333, São Paulo SP, Brazil. 05403-010. aacristante@gmail.com 
Currently, its safety for elderly patients over than 70 years of age has been confirmed, with a risk that is higher than in younger patients, but still acceptable when compared to other techniques. ${ }^{6}$ In this study, we present a minimally invasive extreme lateral approach for the treatment of metastatic lesions in the lumbar spine without the use of the motor evoked potential (MEP).

\section{MATERIALS AND METHODS}

Between February 2014 and May 2015, patients at the São Paulo Cancer Institute with metastatic tumors presenting medullary compression and pathological fractures indicated for anterior approach surgery were treated using the extreme lateral approach. The project was approved by the hospital ethics committee (number 1318) and patients signed a consent form to participate.

A total of two patients were treated: patient 1, an East Asian man, 53 years of age with adenocarcinoma of the colon, Tokuhashi score $^{7}$ of 9 , Tomita score ${ }^{8}$ of 7, Spine Instability Neoplastic Score (SINS) score ${ }^{9}$ of 10; and patient 2, a Caucasian woman, 42 years of age with a clear cell renal cell carcinoma with Tokuhashi of 10, Tomita of 7 and SINS of 11 . Both had lesions in the body of L2, and both had the indication for the procedure due to the presence of lytic lesions affecting the vertebral body and pedicles, resulting in mechanical instability and neurological deficit. Grade 4 motor strength was noted on the left side of levels $L 2$ and $L 3$ in patient 1 and grade 3 strength bilaterally at level $L 2$ in patient 2 , with no changes to the other levels noted in either patient.

The patient under general anesthesia, with orotracheal intubation, is positioned in true right lateral decubitus. Flexion of the table or the patient is performed to increase the distance between the costal arches and the iliac crest of the segment to be operated on (Figure 1A). Assisted by radioscope, the true profile is checked and marks are made on the skin. Asepsis and antisepsis are performed with chlorhexidine-alcohol antigerm solution, and sterile drapes are placed over the site. An oblique approach incision is made (Figure 1B) on the area marked out, noting the primary structures: external oblique, transversus abdominis, and internal oblique muscles. After dilatation of these muscles in the direction of their fibers, the retroperitoneal space is entered. Using digital dissection, the retroperitoneal fat is detached ventrally, creating a space that extends to the anterior edge of the psoas muscle. In both cases presented here, a Syframe (Synthes) retractor was used, and a Pentero (Zeiss) microscope was used in the intercavity approach and lightening.

Because the motor evoked potential (MEP) exam is not always available in the Brazilian public health system, we chose to dislocate the psoas muscle from its anterior edge elevating it. This procedure dismissed the transpsoas approach, which requires MEP evaluation, by avoiding the nerves in the area. The psoas dissection is begun starting at its anterior edge, detaching the muscle from the vertebra and tying off the visible segmental arteries. After adequate retraction, discectomies of the discs above and below the affected vertebra are performed, followed by corpectomy. (Figure 2) For the reconstruction of the anterior and middle structures, an expandable cage (Synex, Synthes) is used alone in both cases. However, the use of a bone graft from the iliac crest or cement is possible, depending on the expected survival of the patients as estimated by the Tokuhashi, Tomita and SINS classifications ${ }^{7-9}$ or by the multidisciplinary oncological clinical impression. Posterior percutaneous pedicular fixation was chosen (Figure 3 ) because it is a procedure that can be performed during the same surgery after a shift to ventral decubitus. Closure is performed by planes with nylon monofilament threads, 2.0 for the deep structures and 3.0 for the skin.

In both cases, immediate postoperative management occurred in the intensive care unit (ICU) and both patients were discharged from the ICU within the first 24 hours following surgery. Pain, rated according to the VAS (visual analog scale), was initially assessed as $5 / 10$ for patient 1 and $7 / 10$ for patient 2, averaging 6/10. The following analgesics were prescribed for both patients: tramadol (100 mg, three times per day), ketoprofen (100 mg twice a day), and acetaminophen (500 mg four times per day).

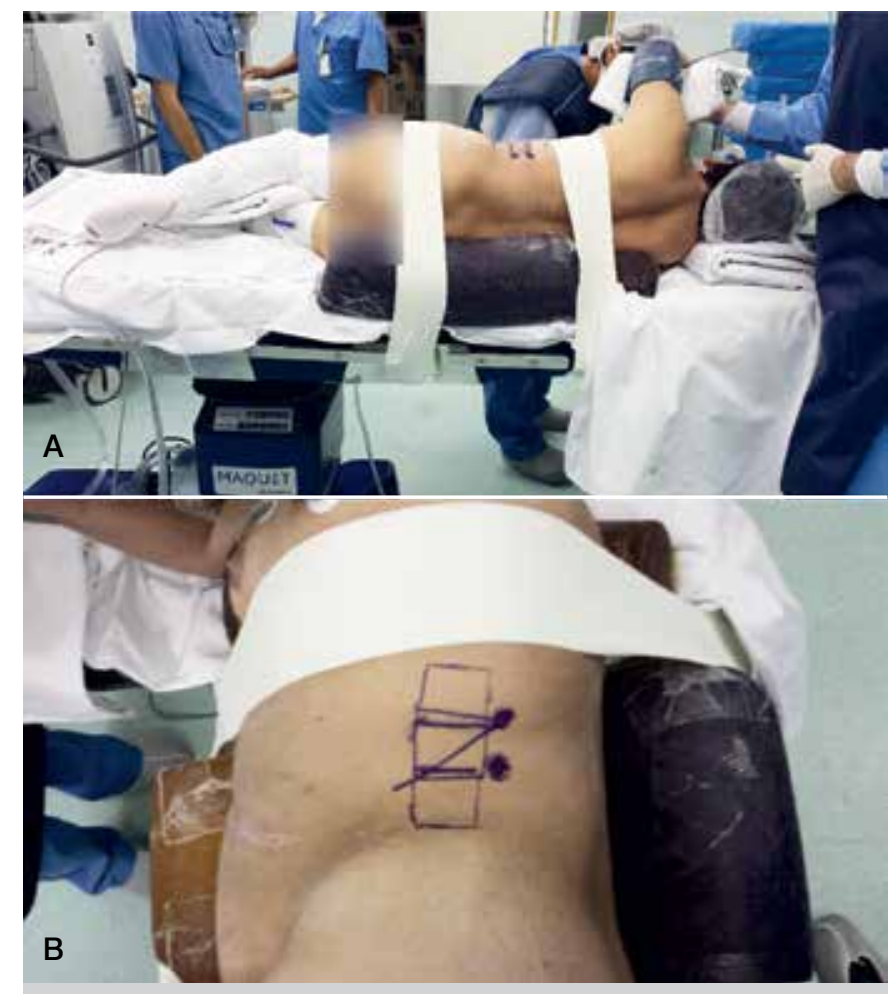

Figure 1. (A) Positioning of the patient; (B) Planning the skin incision.

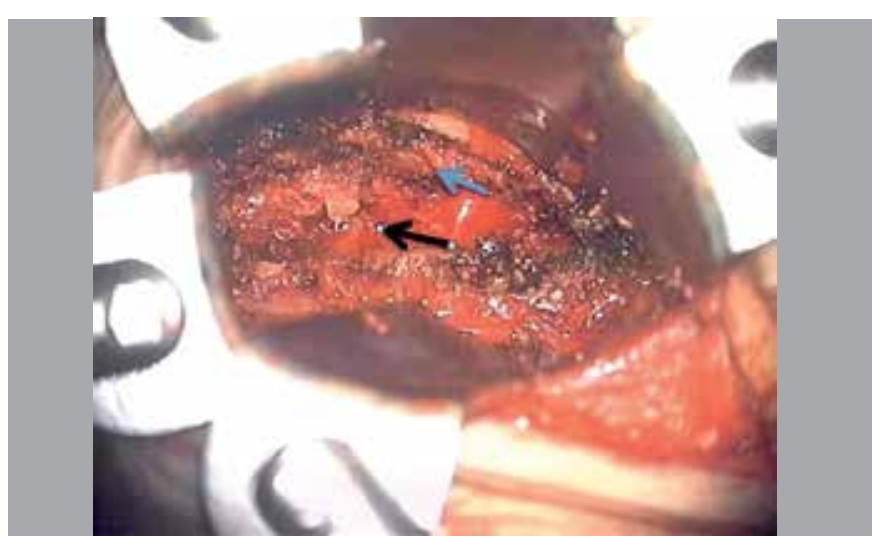

Figure 2. Corpectomy (black arrow) and folded back psoas muscle (blue arrow).

Walking as early as possible was encouraged during the first postoperative day, with the assistance of a trained physical therapist. The dressings were changed and radiographic exams were performed (Figures 4A, 4B). On the second postoperative day, the patients were encouraged to walk without assistance.

On the third postoperative day, pain was at level 2/10 for patient 1 and level 4/10 for patient 2, with an average VAS of 3/10. They were then discharged from hospital.

The stitches were removed at the first hospital follow-up visit, at 14 days, and subsequent follow-up visits took place on a regular basis at 1, 2, 3, 6, and 12 months following surgery. In both cases, post-surgical radiotherapy was performed as an additional method, for local control of the disease.

Patient \#1 was followed-up regularly and suffered from worsening of neurological symptoms (Frankel C) at T10, due to a metastasis at that level. He was operated with decompression, but died in February, 2016, due to lung metastatic complications. Patient \#2 maintained neurological stability (Frankel D), and she was followed up 1 year and 2 months without tumor recurrence. She died later due to sepsis (primary focus in the kidney) during chemotherapy treatment. 


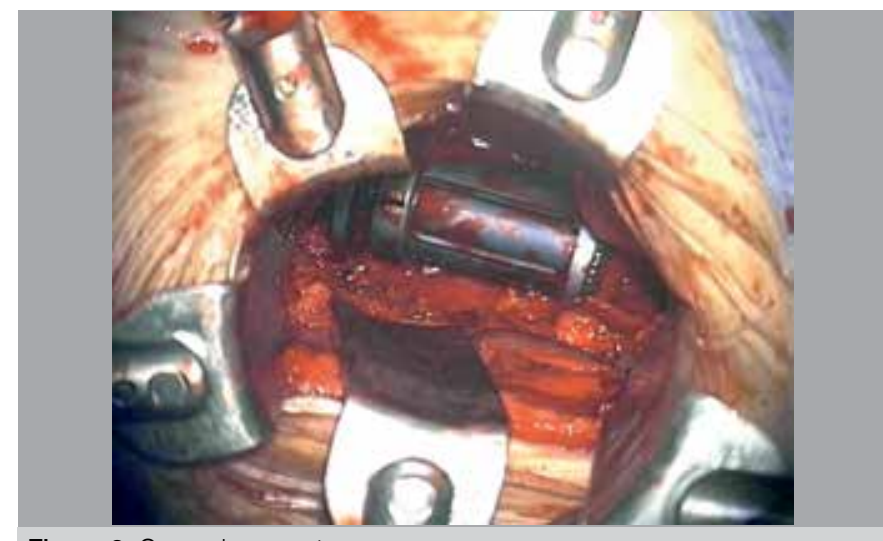

Figure 3. Cage placement

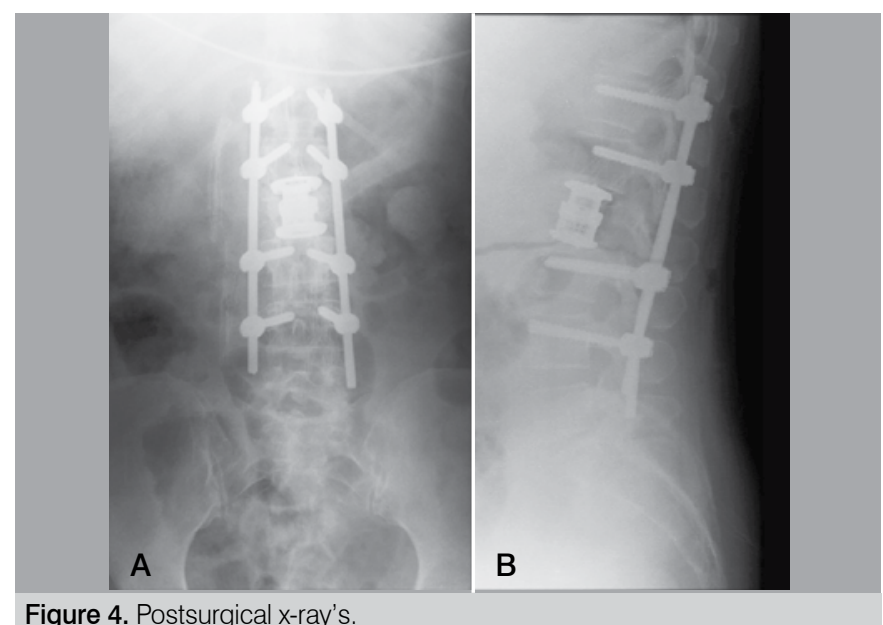

\section{RESULTS}

The surgeries took in average 210 minutes (190-230), including 140 minutes for the extreme-lateral access and 50 minutes for the posterior percutaneous fixation in patient \#1 and 165 minutes for extreme--lateral access and 65 minutes for the posterior percutaneous fixation in patient \#2. Patients' average blood loss was 625 $\mathrm{ml}$ (500 ml for patient \#1 and $750 \mathrm{ml}$ for patient \#2).
There was no neurological impairment. Both patients stayed one day in the ICU postoperatively. Pain score was $6 / 10$ in the immediate postoperative period and $3 / 10$ in the late postoperative period (average visual analogue scale score). Both patients were able to walk with assistance on the first postoperative day, without assistance on the second day, and both were discharged on the third day. Our initial analysis show that minimally invasive techniques can be used in oncological patients, with benefits such as short hospitalization period, low morbidity, minimal risk of infection, which have been shown beneficial in the treatment of degenerative diseases.

\section{DISCUSSION}

Patients with metastatic lesions, once seen as a sign of reserved prognosis and often as the end of the road for cancer treatments, are now handled with more care, focusing on a better quality of life. From the point of view of spine surgery, the implementation of minimally invasive techniques is advantageous. ${ }^{10,11}$ Recent studies have shown shorter hospitalization, similar surgical times, little need for blood components, the non-necessity for a general surgeon, and lower morbidity and mortality. ${ }^{5,10-12}$

When cure is not possible, the use of cytoreduction techniques, like debulking, is still an option. We chose this technique for local disease control and neurological protection. After the surgical procedure, when possible, we still manage the disease with chemotherapy and radiotherapy. The advantage of this method is that this approach can be used even in the absence of the motor evoked potential exam, which is not available everywhere, and takes additional time and resources. Besides being a minimally invasive technique, by the lateral approach, that is able to promote stabilization with small hospitalization times and bleeding, $5,8,11,12$ the technique described here allows treating patients with metastatic diseases using little human and financial resources. By dislocating the psoas, we treated these two patients successfully without the need of MEP equipment or a trained physician in its analysis. Even without using MEP, as expected, there was no degradation of neurological function in neither case in the immediate postoperative period, and an improvement of the motor strength grade was observed in patient 2 in the postoperative period.

\section{CONCLUSION}

The extreme lateral approach can be used as an alternative to conventional approaches where curative resection is not expected. The dislocation of the psoas muscle allows a wider use of the technique in centers where MEP is not available.

Further studies are necessary to make more definitive conclusions about the advantages of this technique.

AUTHORS' CONTRIBUTIONS: Each author made significant individual contributions to this manuscript. AFC (0000-0002-7797-5274)*, TEPBF (00000002-0819-7712)*, and MJT (0000-0002-7974-6045)*: designed the study, interpreted the data, and participated in writing the manuscript; DKN (00000001-7895-4830)*, LCCM (0000-0002-7334-8206)* and WGJT (0000-0001-9036-629X)*: participated in data collection and interpretation and writing the manuscript. All authors revised and approved the final version submitted for publication and are responsible for content of the manuscript. *ORCID (Open Researcher and Contributor ID).

\section{REFERENCES}

1. Ozgur BM, Aryan HE, Pimenta L, Taylor WR. Extreme Lateral Interbody Fusion (XLIF): a novel surgical technique for anterior lumbar interbody fusion. Spine J. 2006;6(4):435-43.

2. Pimenta L, Vigna F, Bellera F, Schaffa T, Malcolm J, McAfee P. A new minimally invasive surgical technique for adult lumbar degener- ative scoliosis. In: Proceedings of the $11^{\text {th }}$ International Meeting on Advanced Spine Techniques (IMAST), Spine Techniques (IMAST), Southampton, Bermuda, July 2004.

3. Phillips FM, Isaacs RE, Rodgers WB, Khajavi K, Tohmeh AG, Deviren V. Adult degenerative scoliosis treated with XLIF: clinical and radiographical results of a prospective multicenter study with 24-month follow-up. Spine (Phila Pa 1976). 2013;38(21):1853-61.

4. Berjano $P$, Lamartina $C$. Far lateral approaches (XLIF) in adult scoliosis. Eur Spine J. 2013;22 Suppl 2:S242-53.

5. Meredith DS, Kepler CK, Huang RC, HegdeVV. Extreme Lateral Interbody Fusion (XLIF) in the Thoracic and Thoracolumbar Spine: Technical Report and Early Outcomes. HSS J. 2013;9(1):25-31.

6. Karikari IO, Grossi PM, Nimjee SM, et al. Minimally invasive lumbar interbody fusion in patients older than 70 years of age: analysis of peri- and postoperative complications. Neurosurgey. 2011;68(4):897-902.
7. Tokuhashi $\mathrm{Y}$, Uei H, Oshima M, Ajiro Y. Scoring system for prediction of metastatic spine tumor prognosis. World J Orthop. 2014;5(3):262-71.

8. Tomita K, Kawahara N, Kobayashi T, Yoshida A, Murakami H, Akamaru T. Surgical strategy for spinal metastases. Spine (Phila Pa 1976). 2001;26(3):298-306.

9. Fisher CG, DiPaola CP, Ryken TC, Bilsky MH, Shaffrey Cl, Berven SH et al A novel classification system for spinal instability in neoplastic disease: an evidence-based approach and expert consensus from the Spine Oncology Study Group. Spine (Phila Pa 1976). 2010;35(22):E1221-9.

10. Lau D, Chou D. Posterior thoracic corpectomy with cage reconstruction for metastatic spinal tumors: comparing the mini-open approach to the open approach. J Neurosurg Spine. 2015;23(2):217-27.

11. Keshavarzi S, Park MS, Aryan HE, Newman CB, Amene CS, Gonda D et al Minimally invasive thoracic corpectomy and anterior fusion in a patient with metastatic disease: case report and review of the literature. Minim Invasive Neurosurg. 2009;52(3):141-3

12. Rao PJ, Thayaparan GK, Fairhall JM, Mobbs RJ. Minimally invasive percutaneous fixation techniques for metastatic spinal disease. Orthop Surg. 2014;6(3):187-95. 